Rodrigo de Faria Valle Dornelles

\title{
Expansão craniana com molas: estudo experimental
}

\author{
em coelhos
}

Dissertação apresentada à Faculdade de Medicina da Universidade de São Paulo para obtenção de título de Mestre em Ciências

Área de concentração: Cirurgia Plástica Orientador: Prof. Dr. Nivaldo Alonso

São Paulo

2009 


\title{
FICHA CATALOGRÁFICA
}

\author{
Dados Internacionais de Catalogação na Publicação (CIP) \\ Preparada pela Biblioteca da Faculdade de Medicina da Universidade de São Paulo \\ Creprodução autorizada pelo autor \\ Dornelles, Rodrigo de Faria Valle \\ Expansão craniana com molas : estudo experimental em coelhos / Rodrigo de \\ Faria Valle Dornelles. -- São Paulo, 2009. \\ Dissertação(mestrado)--Faculdade de Medicina da \\ Universidade de São Paulo. \\ Departamento de Cirurgia. \\ Área de concentração: Cirurgia Plástica. \\ Orientador: Nivaldo Alonso. \\ Descritores: 1.Anormalidades craniofaciais 2.Crânio 3.Craniossinostose \\ 4.Osteogênese por distração 5.Desenho de equipamentos 6.Coelhos \\ USP/FM/SBD-488/09
}




\section{DEDICATÓRIA}

À Luciana, pelo amor e por tolerar as inúmeras horas de afastamento para dedicação ao trabalho.

À Maria Eduarda, quem dá sentido à tudo.

Aos meus pais biológicos, Mario e Helena Maria, que me ensinaram que o estudo é a maior herança.

Aos meus pais científicos, Professor Doutor Roberto Corrêa Chem e Doutora Vera Lúcia Nocchi Cardim. O Doutor Chem, que precocemente nos deixou, ensinou-me os primeiros passos na Microcirurgia e na Cirurgia Plástica e a Doutora Vera, que é um exemplo de dedicação e amor pelos pacientes.

A minha avó Miroca, que com seu espírito artístico, ensinou-me que a vida deve ser aproveitada a cada momento.

Aos meus irmãos, Alexandre e Silvana, que, juntamente com suas famílias, são sempre uma referência e um porto seguro. 


\section{AGRADECIMENTOS}

Ao Professor Doutor Marcus Castro Ferreira, Professor Titular da Disciplina de Cirurgia Plástica da FMUSP, responsável pelo Laboratório de Microcirurgia e Cirurgia Plástica - LIM4, e coordenador do programa de pós-graduação Stricto Sensu em Cirurgia Plástica, pela acolhida e confiança.

Ao Professor Doutor Nivaldo Alonso, responsável pelo Serviço de Cirurgia Craniomaxilofacial da Disciplina de Cirurgia Plástica da FMUSP, pela oportunidade de realizar o projeto e pelo empenho incondicional na orientação dessa dissertação.

À Doutora Vera Lúcia Nocchi Cardim, pela inspiração contínua que oferece aos que a rodeiam e pelos ensinamentos em Cirurgia Plástica e Craniomaxilofacial que nos norteiam.

À Professora Doutora Maria Rita dos Santos e Passos Bueno, do Centro de Estudos do Genoma Humano, que promoveu a integração multidisciplinar imprescindível para a execução do projeto.

À Professora Doutora Marília Trierveiler Martins, da Disciplina de Patologia Bucal da Faculdade de Odontologia da USP, pela dedicação na preparação e interpretação dos cortes histopatológicos. 
À Professora Doutor Ana Carolina Brandão de Campos Fonseca Pinto, pela colaboração que tornou viável a execução dos estudos radiológicos.

Ao Professor Doutor Maurício Conceição Mário, Professor nas áreas de Eletrônica, Computação e Sistemas de Informação da Universidade Santa Cecília, Coordenador do Núcleo de Pesquisas em Eletrônica da Universidade Santa Cecília, que desenvolve trabalhos na área de Inteligência Artificial, utilizando a Lógica Paraconsistente. Pela inestimável colaboração na orientação dos cálculos que possibilitaram a utilização da Lógica Paraconsistente na análise do estudo.

Aos Funcionários do Laboratório Microcirurgia e Cirurgia Plástica LIM4, em especial à Edna, Maria e Silvana, pela colaboração para a realização deste trabalho, com os esclarescimentos institucionais e cuidados dispensados aos animais de experimentação. 


\section{EPÍGRAFE}

"A menos que modifiquemos a nossa maneira de pensar, não seremos capazes de resolver os problemas causados pela forma como nos acostumamos a ver o mundo."

(Albert Einstein) 


\section{NORMALIZAÇÃO ADOTADA}

Esta dissertação está de acordo com as seguintes normas, em vigor no momento desta publicação:

Referências: adaptado de International Committee of Medical Journals Editors (Vancouver)

Universidade de São Paulo. Faculdade de Medicina. Serviço de Biblioteca e Documentação. Guia de apresentação de dissertações, teses e monografias. Elaborado por Anneliese Carneiro da Cunha, Maria Julia de A. L. Freddi, Maria Fazanelli Crestana, Marinalva de Souza Aragão, Suely Campos Cardoso, Valéria Vilhena. 2a ed. São Paulo: Serviço de Biblioteca e Documentação; 2005.

Abreviaturas dos títulos dos periódicos de acordo com List of Journals Indexed in Index Medicus. 


\section{SUMÁRIO}

Lista de Figuras

Lista de Tabelas

Lista de Gráficos

Lista de Abreviaturas

Lista de Símbolos

Lista de Siglas

Resumo

Summary

1 INTRODUÇÃ

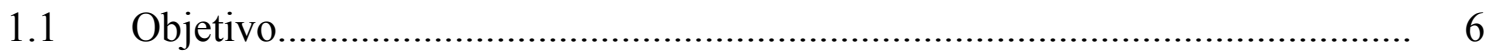

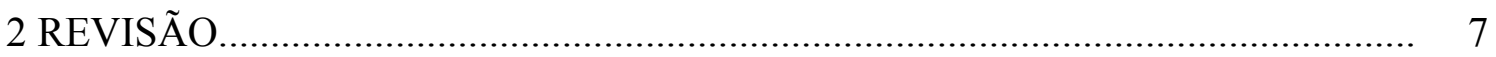

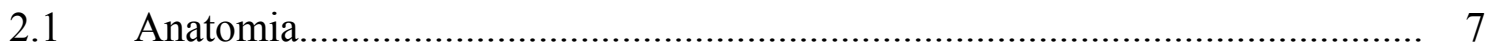

1.1 Embriologia e crescimento............................................................... 20

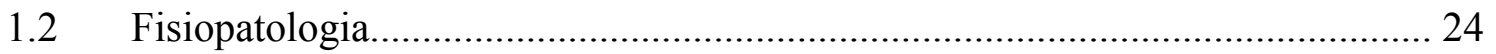

1.3 Classificação das craniossinostoses não sindrômicas..................................... 28

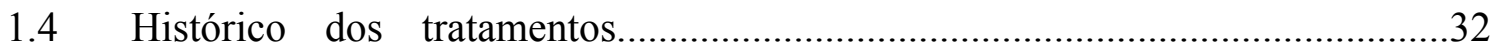

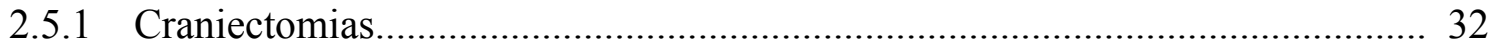

2.5.2 Distração osteogênica........................................................................... 37

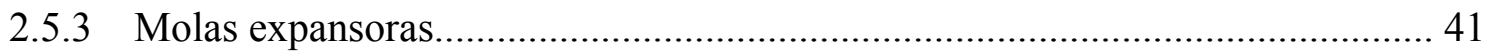




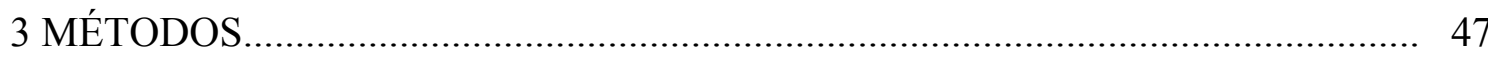

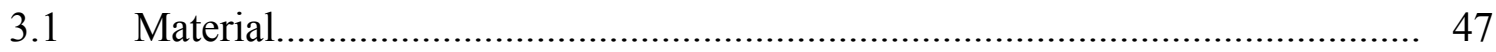

3.2 Mola

3.3 Cronograma

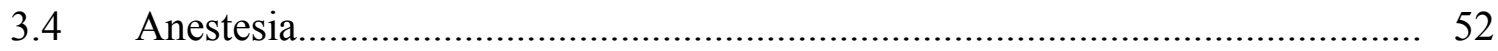

$3.5 \quad$ Antissepsia

3.6 Técnica Operatória.................................................................................. 53

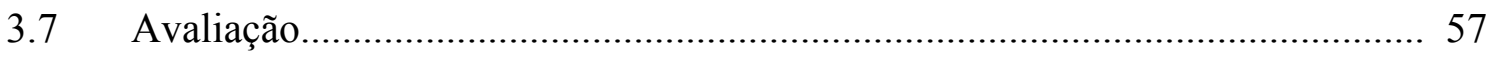

3.7.1 Avaliação histopatológica......................................................................... 58

3.7.1.1 Preparo do material para avaliação histopatológica............................................... 58

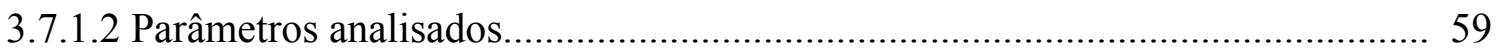

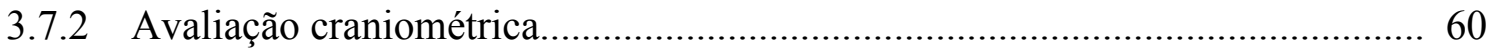

3.7.3 Método de avaliação dos dados....................................................................... 67

3.7.3.1 Metodologia usada para determinação do grau de evidência de anormalidade de

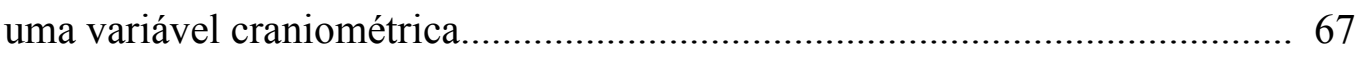

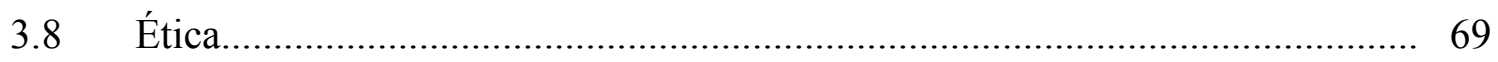

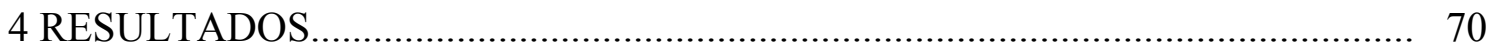

4.1 Aspectos radiológicos.......................................................................... 70

4.2 Aspectos histopatológicos................................................................... 73

4.2 Aspecos da Lógica Paraconsistente.............................................................. 79

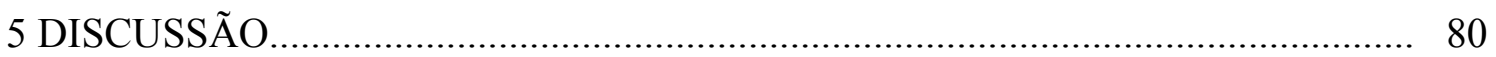




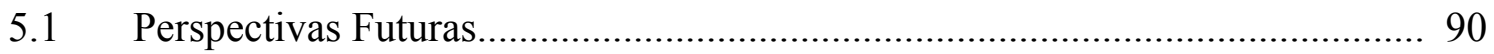

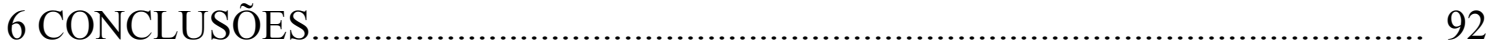

7 ANEXOS

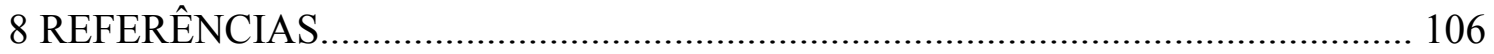




\section{LISTA DE FIGURAS}

Figura 1 Crânio com Craniossinostose de um Homo heilderbergensis............ 01

Figura 2 Fukurokuju, Deus japonês da Felicidade, da boa sorte e prosperidade... 02

Figura 3 Shou-Xing, Deus chinês do tempo, das estrelas e da imortalidade......... 02

Figura 4 Crânio Pré-Colombiano...................................... 03

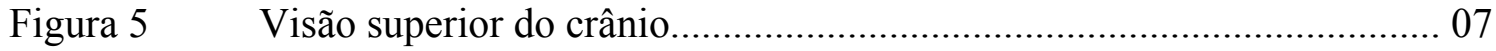

Figura 6 Representação esquemática dos ossos do crânio e localização das

suturas e fontanelas de um recém-nascido....................................... 08

Figura $7 \quad$ Osso frontal, visão anterior........................................................ 10

Figura $8 \quad$ Osso parietal direito, visão externa............................................... 11

Figura 9 Osso parietal direito, visão interna................................................... 12

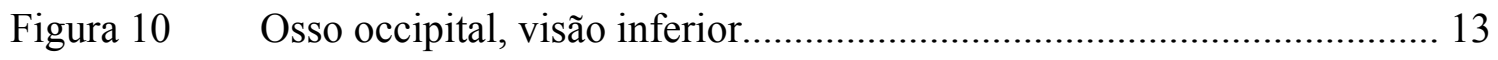

Figura $11 \quad$ Osso occipital, visão superior............................................................ 14

Figura 12 Osso temporal direito, visão externa................................................. 15

Figura 13 Osso temporal, visão externa e suas partes....................................... 16

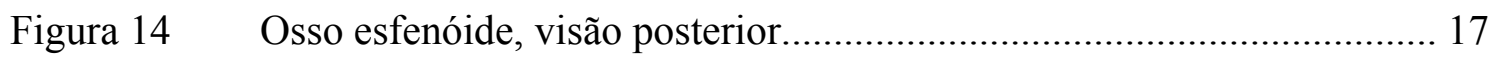

Figura $15 \quad$ Osso esfenóide, visão anterior................................................... 18

Figura 16 Osso etmóide, visão lateral esquerda............................................... 19

Figura 17 Osso etmóide, visão inferior....................................................... 19

Figura 18 Anatomia do crânio do coelho..............................................................20 
Figura 19 Ilustração de escafocefalia............................................................... 29

Figura $20 \quad$ Ilustração de trigonocefalia.............................................................. 30

Figura 21 Ilustração de plagiocefalia.............................................................. 31

Figura 22 Ilustração de braquicefalia........................................................... 32

Figura 23 Tratamento cirúrgico da plagiocefalia, com grande área de descolamento, tanto subperiostal, quanto intracraniano. Necessidade de reconstrução conjunta da barra orbital............................................................. 37

Figura 24 Tratamento cirúrgico da trigonocefalia, também com grande área de descolamento. A: visão lateral e B: visão anterior.............................. 37

Figura 25 Tratamento de escafocefalia com o uso de placas absorvíveis. A: "back table" com montagem da nova conformação dos ossos parietais, frontal e occipital e B: após reposicionamento.............................................. 38

Figura 26 Exemplo de distração osteogênica mandibular, feita em um caso de Microssomia Hemicraniofacial............................................................. 40

Figura 27 Distrator ósseo externo, implantado em osteotomias lineares parassagitais em um caso de escafocefalia 41

Figura 28 Paciente com escafocefalia. A: visão frontal pré-operatória; B: visão de perfil pré-operatória; $\mathrm{C}$ : transoperatório após craniotomias parassagitais bilaterais e a colocação das molas 44

Figura 29 A: Rx de perfil e B: anteroposterior, pré-operatório de paciente portador de escafocefalia, pode-se notar o sinal da prata batida, que é a impressão 
das circunvoluções cerebrais na tábua óssea interna visíveis no exame radiológico. C e D: Pós-operatório de 30 dias, das mesmas incidências, demonstrando o afastamento das margens ósseas das osteotomias

parassagitais 54

Figura 30 Imagens da cirurgia de retirada das molas, demonstrando o afastamento das extremidades, a ossificação da área de distração e o mínimo descolamento subperiostal para efetuar a retirada...................... 46

Figura 31 A: imagem do perfil de pré-operatório; B: perfil pós-operatório com 2 anos e quatro meses de evolução e C: controle tomográfico do pósoperatório, demonstrando a ossificação das áreas de distração óssea..... 46

Figura 32 Localização dos marcadores de amálgama e da mola............................... 50

Figura 33 Imagem da mola. Linha vermelha: distância entre o afastamento das extremidades de apoio. Linha verde: braço da mola 51

Figura 34 Posicionamento do animal após anestesia e tricotomia. 52

Figura 35 A: visão do afastamento das partes moles e exposição da área a ser operada no crânio. B: visão do descolamento periostal suficiente para a implantação dos marcadores de amálgama e para a craniotomia 53

Figura 36 A: Imagem da broca utilizada; B: Imagem da suturectomia sagital com os orifícios para implantação dos marcadores dos amálgamas e C: Imagem após a implantação dos marcadores de amálgama. 54

Figura 37 Imagem da incisura realizada à distância intermediária entre M2 e M3. 55 
Figura 38 Imagem após colocação da mola no Grupo III...................................... 56

Figura 39 Imagem da colocação da mola no Grupo IV ....................................... 57

Figura 40 Imagem da retirada da calota craniana envolvendo a área de implantação dos amálgamas e da colocação da mola........................... 58

Figura 41 Imagem do posicionamento do animal para o exame de RX.A: decúbito ventral para a imagem ventrodorsal e B: decúbito lateral direito........... 61

Figura 42 Imagens das incidências radiológicas.A: ventrodorsal e B: lateral......... 62

Figura 43 Diagrama esquemático para os pontos craniométricos utilizados na medição do comprimento da base craniana...................................... 63

Figura 44 RX com exemplo da medição linear dos pontos da base do crânio........ 64

Figura 45 Diagrama esquemático do crânio de coelho, visão lateral, com os pontos

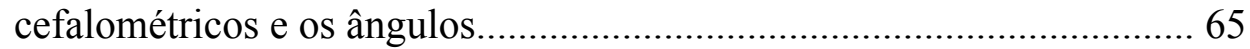

Figura 46 RX com exemplo das medições angulares feitas com o programa de computador MIRROR $^{\circledR}$ no coelho G IV 12 semanas.......................... 66

Figura 47 Cortes histopatológicos obtidos com 2 semanas dos grupos II, III e IV respectivamente de cima para baixo. Evidencia-se a deposição óssea a partir das margens e da profundidade nos grupos III e IV ................. 75

Figura 48 Cortes histopatológicos obtidos com 4 semanas dos grupos II, III e IV respectivamente de cima para baixo. No grupo II a região da superfície interna do osso demonstra menor quantidade de neoformação com 
relação à superfície externa. Há tecido ósseo imaturo unindo as

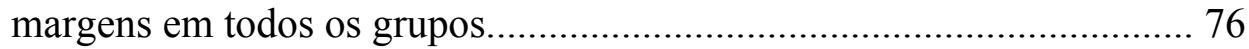

Figura 49 Cortes histopatológicos obtidos com 8 semanas dos grupos II, III e IV respectivamente de cima para baixo. Na região mais interna, a deposição óssea está em estágio menos avançado, e ainda é possível notar-se tecido conjuntivo jovem, embora já sem a presença de infiltrado inflamatório.77

Figura 50 Cortes histopatológicos obtidos com 12 semanas dos grupos II, III e IV respectivamente de cima para baixo.............................................. 78 


\section{LISTA DE TABELAS}

Tabela 1 Convenção de cada animal conforme o grupo e o momento do estudo.. 93

Tabela 2 Distribuição cronológica para otimização da execução do projeto......... 93

Tabela 3 Anotações do peso em gramas de cada indivíduo no pré-operatório e pósoperatório de cada momento estudado e a média de incremento no

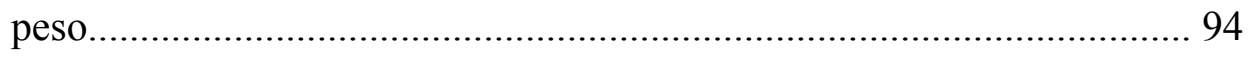

Tabela 4 Ângulos medidos no Grupo I............................................................ 94

Tabela 5 Ângulos medidos no Grupo II.......................................................... 95

Tabela 6 Ângulos medidos no Grupo III........................................................ 95

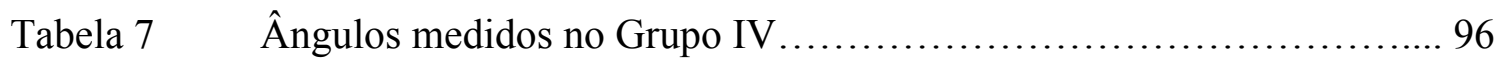

Tabela 8 Medidas lineares em centímetro da base do crânio anterior............. 96

Tabela 9 Medidas lineares em centímetro da base do crânio posterior............ 97

Tabela 10 Medidas lineares em centímetro da placa cribriforme................. 97

Tabela 11 Medidas lineares em centímetro da base craniana total............... 97

Tabela 12 Medidas lineares em centímetro entre os marcadores de amálgama..... 98

Tabela 13 Medidas lineares em centímetro entre o marcador de amálgama M3, em

todos os grupos, mensuradas com duas, quatro, oito e 12 semanas........ 71

Tabela 14 Resultados da observação histopatológica dos grupos II, III, IV em cada momento estudado com a graduação dos parâmetros......................... 74 


\section{LISTA DE GRÁFICOS}

Gráfico 1 Demonstração gráfica do afastamento, em centímetro, dos amálgamas da posição M3 em todos os Grupos em cada um dos momentos

estudados.................................................... 71

Gráfico 2 Demonstração gráfica da variação do comprimento da base craniana de todos os Grupos nos momentos estudados............................ 72

Gráfico 3 Demonstração gráfica da variação angular BO'/NO...................... 98

Gráfico 4 Demonstração gráfica da variação angular BO'/RhN................... 99

Gráfico 5 Demonstração gráfica da variação angular BO'/MaO................... 99

Gráfico 6 Demonstração gráfica da variação angular BO'/PL.................... 100

Gráfico 7 Demonstração gráfica da variação angular BO'/MpS.................. 100

Gráfico 8 Demonstração gráfica da variação angular BO'/LS.................... 101

Gráfico 9 Demonstração gráfica da variação angular BO'/JO.................... 101

Gráfico 10 Demonstração gráfica da variação do ângulo BO'/Boi............................. 73

Gráfico 11 Demonstração gráfica da contextualização das medidas do ângulo

BO'/Boi....................................................... 102

Gráfico 12 Demonstração gráfica da contextualização das medidas do ângulo

BO'/NO..................................................... 102

Gráfico 13 Demonstração gráfica da contextualização das medidas do ângulo 


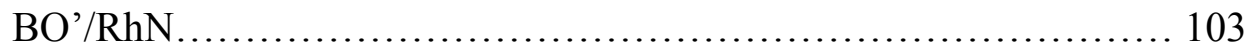

Gráfico 14 Demonstração gráfica da contextualização das medidas do ângulo

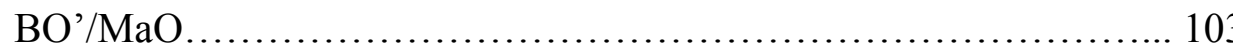

Gráfico 15 Demonstração gráfica da contextualização das medidas do ângulo BO'/PL........................................................... 104

Gráfico 16 Demonstração gráfica da contextualização das medidas do ângulo

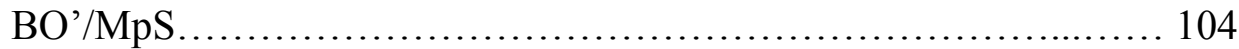

Gráfico 17 Demonstração gráfica da contextualização das medidas do ângulo

BO'/LS....................................................... 105

Gráfico 18 Demonstração gráfica da contextualização das medidas do ângulo

BO'/JO ..................................................... 105 


\section{LISTA DE ABREVIATURAS}

\begin{tabular}{|c|c|}
\hline a.C. & antes de Cristo \\
\hline FGFR & fator de crescimento fibroblástico (fibroblast growth factor receptor) \\
\hline TWIST & $\begin{array}{l}\text { gene do cromossomo } 7 \mathrm{p} 21-22 \text {. regulador da morfogênese embrionária } \\
\text { (basic helix-loop-helix transcription factor) }\end{array}$ \\
\hline MSX2 & gene do cromossomo 5q34-q35Muscle segment box(1) \\
\hline TGF- $\beta$ & fator de crescimento transformante beta (transforming growth factor) \\
\hline BMP & proteína morfogenética do osso (bone morphogenetic proteins) \\
\hline NOGGIN & antagonista da BMP \\
\hline $\mathrm{RX}$ & raio $\mathrm{X}$ \\
\hline PIC & pressão intracraniana \\
\hline G I & grupo I \\
\hline G II & grupo II \\
\hline G III & grupo III \\
\hline G IV & grupo IV \\
\hline M1 & marcador 1 \\
\hline M2 & marcador 2 \\
\hline M3 & marcador 3 \\
\hline M4 & marcador 4 \\
\hline $\mathrm{HE}$ & hematoxilina eosina \\
\hline
\end{tabular}


FE-P comprimento da placa cribriforme (base craniana anterior)

P-S comprimento pré-esfenóide

S-B comprimento posterior da base do crânio

O ponto no centro do forâmen óptico

Oi ponto mais profundo no contorno externo do osso occipital entre o forame magno e a protuberância occipital externa

Mp ponto mais posterior na marca anterior no osso parietal esquerdo

Ma ponto mais anterior na marca posterior no osso frontal esquerdo

J extremidade do sulco endocraniano onde o osso frontal separa as fossas anterior e média do cranio

S ponto mais profundo na sincondrose esfeno-occipital cartilaginosa

PL uma linha tangencial até a borda inferior do palato duro

BO’ a extensão da linha através dos pontos B e O.

BO'/PL (ângulo maxilo-basilar) ângulo formado entre e abaixo das linhas BO’ e PL

BO'/RhN (ângulo rino-basilar) ângulo formado entre e acima das linhas BO' e RhN BO'/NO (ângulo naso-basilar) ângulo formado entre e acima das linha BO' e NO BO'/JO (ângulo basilar-olfatório) ângulo formado entre e acima das linhas BO'e JO

BO'/MaO (ângulo marca anterior-basilar) ângulo formado entre e acima das linha BO’ e $\mathrm{MaO}$ 
BO'/MpS (ângulo marca posterior-basilar) ângulo formado entre e acima das linhas BO’ e MpS

BO'/LS (ângulo lambdóide-basilar) ângulo formado entre e acima das linhas BO' e LS

BO'/BOi (ângulo foramino-basilar) ângulo formado entre e acima das linhas BO' e Boi

EEB Equação Estrutural Básica da Lógica Paraconsistente

Sem semana 


\section{LISTA DE SÍMBOLOS}

\begin{tabular}{|c|c|}
\hline $\mathrm{F}$ & Força \\
\hline $\mathrm{K}$ & constante Newton/metro \\
\hline$\Delta 1$ & variável em metros \\
\hline $\mathrm{mg}$ & miligrama \\
\hline $\mathrm{g}$ & grama \\
\hline${ }^{\circ} \mathrm{C}$ & graus Celsius \\
\hline " & polegada \\
\hline $\mathrm{N}$ & Newton \\
\hline $\mathrm{mg} / \mathrm{Kg}$ & miligrama por quilo \\
\hline$\%$ & por cento \\
\hline “":" & relação \\
\hline $\mathrm{mm}$ & milímetro \\
\hline $\mathrm{UI} / \mathrm{Kg}$ & Unidades Internacionais por quilo \\
\hline $5-0$ & espessura do fio de sutura \\
\hline$\mu \mathrm{m}$ & micrômetro \\
\hline $\mathrm{mA}$ & miliampère \\
\hline $\mathrm{kV}$ & quilovolt \\
\hline $\mathrm{cm}$ & centímetro \\
\hline
\end{tabular}




$\begin{array}{ll}\text { CO2 } & \text { Dióxido de carbono } \\ \mathrm{X} & \text { vezes (magnificação) } \\ \mathrm{x} & \text { normalização } \\ \mu \mathrm{r} & \text { grau de evidência resultante } \\ \mu & \text { evidência favorável } \\ \lambda & \text { evidência contrária } \\ \mathrm{y} & \text { medida normalizada } \\ \mathrm{h} & \text { horas }\end{array}$




\section{LISTA DE SIGLAS}

$\begin{array}{ll}\text { FMUSP } & \text { Faculdade de medicina da Universidade de São Paulo } \\ \text { LIM4 } & \text { Laboratório de Microcirurgia Experimental } \\ \text { COBEA } & \text { Colégio Brasileiro de Experimentação Animal } \\ \text { SI } & \text { Sistema Internacional de Unidades } \\ \text { USP } & \text { Universidade de São Paulo } \\ \text { HE } & \text { Hematoxilina-eosina } \\ \text { CAPPesq } & \text { Comissão de Ética para Análise de Projetos de Pesquisa } \\ \text { Le Fort } & \text { Classificação de fraturas da face }\end{array}$




\section{RESUMO}

DORNELLES, RVF. Expansão Craniana com molas: estudo experimental em coelhos [dissertação]. São Paulo: Faculdade de Medicina, Universidade de São Paulo; 2009.

A expansão craniana com o uso de molas tem demonstrado eficácia no tratamento das anormalidades craniofaciais, tais como as craniossinostoses. A ação expansora exercida pelas molas tem sido observada tanto quando colocadas entre as margens parietais dos ossos do crânio, como quando lateralmente à sutura sagital, principalmente nas escafocefalias. No presente estudo foi criado um modelo experimental com coelhos, e feita uma avaliação descritiva do comportamento da calota craniana e das suturas sob ação de molas. Foram utilizados 13 coelhos Nova Zelândia com quatro semanas de vida, divididos em quatro grupos: grupo I, foram implantados no crânio marcadores de amálgama para controle; no grupo II, marcadores de amálgama e osteotomia da sutura sagital; no grupo III, marcadores de amálgama, osteotomia da sutura sagital e colocação de uma mola expansora na região interparietal e, no grupo IV, marcadores de amálgama, craniotomia parassagital linear com colocação da mola. Os animais foram sacrificados com duas, quatro, oito e doze semanas. Foi realizado controle radiológico com avaliação do afastamento dos marcadores de amálgama, da variação dos ângulos cefalométricos e das medidas da base do crânio, bem como um estudo histopatológico da região de colocação das molas. Nos grupos com o uso de molas a separação dos bordos da craniotomia foi maior do que naqueles sem a utilização 
de mola. Houve ossificação em todos os grupos, com maior rapidez no grupo II. O crescimento ósseo deu-se a partir dos bordos e da profundidade. Não foram observadas diferenças significativas no padrão histopatológico da regeneração óssea entre os grupos com colocação de mola na região interparietal e parassagital. O modelo experimental com coelhos se mostrou adequado às análises propostas pelo estudo. Concluiu-se que houve osteogênese por distração nos grupos III e IV e que apresentaram uma expansão craniana semelhantes.

Descritores: Anormalidades craniofaciais, crânio, craniossinostose, osteogênese por distração, desenho de equipamento, coelhos. 


\section{SUMMARY}

DORNELLES, RVF. Spring-mediated skull expansion: experimental study in rabbits [dissertation]. São Paulo: School of Medicine, University of São Paulo; 2009.

Spring-mediated skull expansion has proven to be effective in the treatment of craniofacial abnormalities, such as craniosynostosis. The use of springs in cranial expansion has been studied both in the sagittal and in parasagittal regions, especially in scaphocephaly. A rabbit model was used in the present study to analyze the effects of springs on the cranial vault and sutures. Thirteen 4-week-old New Zealand rabbits were used and divided into 4 groups: group I, amalgam markers were used as control; in group II, amalgam markers and osteotomy of the sagittal suture; in group III, amalgam markers and osteotomy of the sagittal suture with implant of an expansible spring in the interparietal region and in group IV, amalgam markers and linear parasagittal craniectomy with springs. Animals were sacrificed after 2, 4 and 12 weeks. Radiological control with assessment of the amalgam markers, variation of cephalometric angles and cranial base measurements, as well as the histopathological analysis of the spring implant area were carried out. In the groups using springs distraction of the craniectomy borders was greater than in those that did not use springs. Ossification was observed in all of the groups and was faster in group II. Bone growth started from the borders and depth. There were no significant differences in the histopathological pattern of bone regeneration between the groups with spring implant in the interparietal and parasagittal 
region. The rabbit model proved to be adequate for the analysis proposed by the study. It was concluded that there was osteogenesis caused by distraction in groups III and IV, with similar skull expansion rates.

Describers: Craniofacials abnormalitys, skull, craniosynostosis, osteogenesis for distraction, equipment design, rabbits. 


\section{INTRODUÇÃO}

Paleontólogos descobriram o crânio de um Homo heilderbergensis, antepassado do Neandertal de 530 mil anos, o qual pertenceu a uma criança de 5 a 12 anos de idade com craniossinostose, na província espanhola de Burgos (Figura 1).

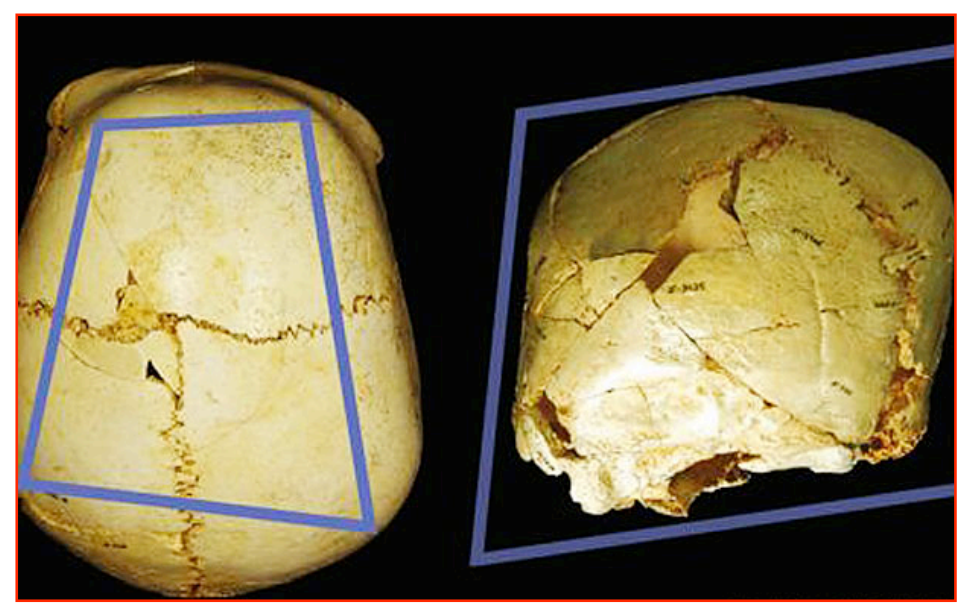

Figura 1. Crânio com Craniossinostose de um Homo heilderbergensis

Houve tempo em que as malformações craniofaciais eram tidas como causas divinas ou sobrenaturais, há figuras de deuses na China que retratam cabeças altas ou com grandes projeções da região frontal (Fukurokuju, Figura 2, e Shou-Xing, Figura $3)^{(1)}$. 


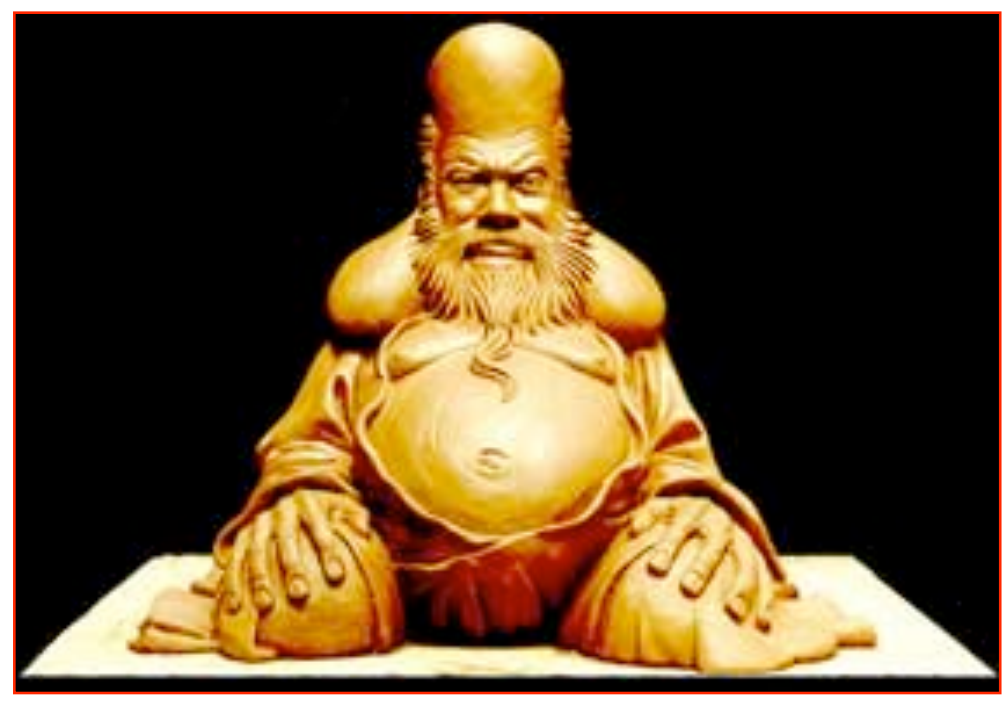

Figura 2. Fukurokuju, Deus japonês da Felicidade, da boa sorte e prosperidade

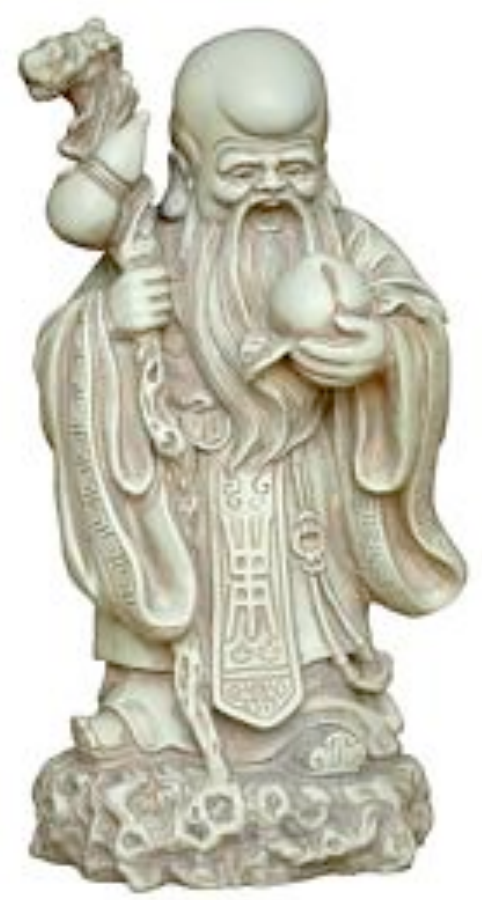

Figura 3. Shou-Xing, Deus chinês do tempo, das estrelas e da imortalidade 
Tal aspecto chegou a ponto de que a deformação craniana intencional fizesse parte cultural de povos antigos (Figura 4). Nas Américas, datam de 8000 a.C., sendo que essa tradição só cessou em 1752 sob o domínio colonial espanhol. Como consequência da deformação intencional, por distorção das direções normais de crescimento craniano, há uma alteração do processo normal do fechamento das suturas cranianas. Vários desses crânios apresentaram ossificação precoce das suturas, enquanto que outros apresentaram suturas que ficaram sem se fechar até a idade mais avançada ${ }^{(2,3)}$.

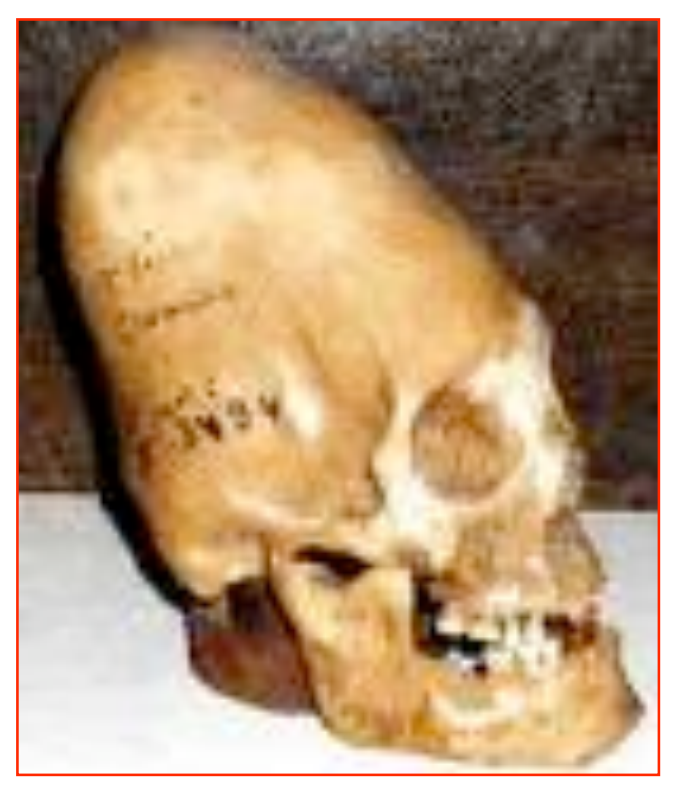

Figura 4. Crânio Pré-Colombiano.

A famosa obra "De Vulneribus Capitis Liber", Hipócrates (460-367 a.C.), apud Guimarães-Ferreira et al. ${ }^{(1)}$, inicia com a frase: “As cabeças humanas não são similares 
entre si. Nem são as suturas constantes em número e localização", evidenciando que a inconstância das suturas cranianas e os fechamentos das mesmas já eram observados.

As suturas craniofaciais são regiões importantes de crescimento ósseo facial e craniano, têm seu desenvolvimento maior durante a embriogênese, e desempenham duas funções importantes:

1) manter da maleabilidade do crânio durante a passagem pelo canal de parto;

2) permitir a separação entre os ossos do crânio durante a vida intrauterina e perinatal.

A craniossinostose é a fusão prematura de uma ou mais suturas do crânio com consequente deformidade craniana e/ou facial, afetando aproximadamente um entre 1700 a 4000 nascidos $\operatorname{vivos}^{(4)}$. Além da forma, a função pode estar também comprometida, pois a limitação no desenvolvimento pode implicar hipertensão intracraniana, distúrbios visuais, retardo mental e outras anomalias ${ }^{(1,4)}$.

Lycosthene (1557) descreveu uma criança com uma deformidade de crânio e membros, a síndrome de acrocefalossindactilia, posteriormente descrita por Apert $(1906) *$ apud McCarthy et al. ${ }^{(5)}$.

* Apert, E. De l'acricephalosyndactylie. Bull Soc Med Hop. (Paris). 1906; 23:1310 
O termo craniossinostose foi usado pela primeira vez por Otto em $1830^{(5,6)}$, porém, em 1851, Rudolf Ludwig Carl Virchow* apud Persing et al. ${ }^{(7)}$, publicou um artigo que tem importância até os dias de hoje, no qual descreve uma série de 29 crânios malformados na tentativa de elucidar casos de cretinismo. Cita os autores Stahl, Gibson e Sommering, e Hyrtl como precursores da idéia de que o fechamento precoce de uma sutura craniana leva à deformação do crânio, entretanto, indica as compensações durante o crescimento e tenta estabelecer padrões gerais predictivos.

\footnotetext{
* Virchow, R. Üeber den Cretinismus, namentlich in Franken, und üeber pathologische Schädelformen.
} Verh Physikalisch Med Ges. (Wurxburg). 1851; 2:230 


\subsection{Objetivo}

O objetivo do presente estudo é:

- Avaliar os resultados da implantação de molas expansoras na região interparietal e parassagital, após craniectomia, em coelhos, através de análise radiológica e histopatológica. 